\title{
Clever girls' stories: the girl they call a nerd
}

\author{
Trine Foyn $^{1} \cdot$ Yvette Solomon $^{1,2}$ (D) \\ Hans Jørgen Braathe ${ }^{1}$
}

Published online: 25 January 2018

(C) The Author(s) 2018, corrected publication February/2018. This article is an open access publication

\begin{abstract}
In this paper, we explore the issue of gender and mathematics participation, focusing on the ways in which "clever girls" self-author within the discourse order of a high ability group, which has particular significance in the Norwegian context in which this study took place. Contrasting the cases of three girls, only one of whom (Anna) chooses to continue with a higher level of mathematics (mathematics for science), we consider the ways in which they manage being members of the "smart group". We analyse in particular the storying of Anna as a "nerd" and the social cost of being a "clever girl" against the backdrop of a public discourse of equality of opportunity in Norway.
\end{abstract}

Keywords Girls' participation in mathematics $\cdot$ Norwegian gender equality discourses $\cdot$ Ability grouping policy $\cdot$ High achievers $\cdot$ Identity

\section{Introduction: addressing girls' participation in mathematics in Norway}

Until the mid-1990s, much research focused on the fact that girls scored lower than boys in mathematics (Paechter, 2001), but today we see no significant gender differences in international tests such as PISA. Reporting on the situation in Norway, where this study took place, Nordtvedt (2013) concluded that PISA 2012 showed no significant gender differences in terms

Yvette Solomon

y.solomon@mmu.ac.uk

Trine Foyn

Trine.Foyn@hioa.no

Hans Jørgen Braathe

HansJorgen.Braathe@hioa.no

1 Faculty of Education, OsloMet - Oslo Metropolitan University, Postboks 4. St. Olavs Plass, 0130 Oslo, Norway

2 Education and Social Research Institute, Manchester Metropolitan University, M20 2RR Manchester, England 
of results in mathematics. However, differences emerge when it comes to choosing mathematics in post-compulsory education: despite a strong public discourse of gender equality in Norway, the international pattern of girls' and women's decreasing participation beyond the compulsory years (Forgasz, Becker, Lee, \& Steinthorsdottir, 2010) is also visible there. This paper explores the way in which three Norwegian girls self-author within the discourse order of a high ability group: this context has particular significance in equity-conscious Norway, where ability grouping has until recently been disallowed and even now must only be temporary. We note the risks and social cost of being a girl who is successful in mathematics, and question the claim that introducing ability grouping can address girls' low post-compulsory participation.

In the Norwegian school system, students beginning high school (grades 11 and 12, ages 16-17) must choose between various broad study pathways, which entail different types of mathematics. The natural science pathway requires students to take theoretical mathematics for science; the social science pathway requires applied mathematics for social science, while arts and crafts and other practical pathways require study of basic level mathematics only. However, even though in 2009 48\% of grade 11 students choosing theoretical mathematics on science pathways were girls, having entered high school with on average better results in mathematics than boys, their participation by grade 13 had dropped to only about $40 \%$, in contrast to around 55\% in mathematics for the social sciences (Bjørkeng, 2011). Likening her results to Turmo's (2007) analysis of the results of TIMSS, PISA and PIRLS, Bjørkeng (2011) concludes that "although girls often have equally good science results as boys, they have less motivation and poorer perception of their skills" (p. 21), a view which reappears in Jensen and Nordtvedt's (2013) analysis.

As elsewhere, Norwegian TIMSS and PISA performance results and their indication of a mediocre standing in world rankings have led to a debate on teaching quality and raising standards. One aspect of this debate has been an increased focus on high achieving students, especially in the sciences and mathematics (Nissen, Kyed, Baltzer, \& Skogen, 2012; Skogen \& Idsøe, 2011). This focus has major significance within the Norwegian context, since its education system is historically rooted in a social democratic egalitarian ideology which has declared anything more than temporary ability grouping illegal (Ministry of Education and Research, 1998). This outlook has however come under pressure in recent years from arguments that the needs of higher achieving students are ignored within this policy. Thus, the introduction of a new curriculum in 2006 replaced the practice of differentiation by depth and breadth within the whole class with "adjusted education" for individual students, opening the door to the possibility of organising students into ability groups, although permanent groups over periods longer than one school year continued to be disallowed.

In 2014, the Norwegian government assembled a group of experts to explore the organisation of science and mathematics teaching, addressing in particular the problem of low recruitment to advanced courses in science and mathematics in upper secondary school. In addition to suggesting that high achievers should be given opportunities to take more advanced courses than average for their age group (i.e., in a move towards "accelerating" learning rather than the earlier policy focus on depth and breadth, or enrichment), they also raised the issue of ability grouping for these students:

It can be challenging for teachers to provide an adequate service to high performing students within the framework of the classroom, and other educational measures should be used in addition to differentiation. High performing students may benefit from a stimulating learning community with peers, where they are motivated to work with 
science subjects. It is important that such students are offered the opportunity for both academic and social maturation, and so measures should be put in place that give students the opportunity not only to meet other high performing students, but especially their high performing peers. (Ministry of Education and Research, 2014, p. 75, our translation)

This formulation represents a political move towards a general acceptance of ability grouping as a pedagogical necessity, and as part of the greater good in terms of addressing the need to recruit high performing students into science and mathematics. Note, however, the ongoing presence of a traditional Norwegian educational emphasis on the development of the "whole child" (i.e., in their social maturation) and on community; this remnant of "bildung" might perhaps be paying lip service only to a former education ethos, but we take this idea seriously in what follows. Given girls' lower participation in science pathways, higher performing girls are among those targeted by these suggestions, and we might ask whether they are well served by this legitimisation of ability grouping: how do they experience being in a high ability group in terms of their social positioning and the value for them of being "good at mathematics?"

\section{Classroom cultures, gender and identity in mathematics}

A large body of work identifies the role of school cultures in students' experiences of mathematics, much of it focusing on the consequences of ability grouping for girls. For example, Boaler (1997a, 1997b) reports that high achieving girls experience more stress, anxiety and dissatisfaction in mathematics classes, particularly within classroom cultures which value speed and apparent effortlessness (see also Boaler, Wiliam, \& Brown, 2000). This dominant classroom culture appears to favour boys, especially those in "higher sets", where girls are likely to feel out of place and may describe boys as better mathematicians than themselves (Solomon, 2007). Indeed, Bartholomew (2005) noted how readily boys in higher ability groups enacted a role of "budding mathematician" equal to the teacher, a position which Black (2004) observed in nascent form in an English primary school, where middle class boys participated in dialogue with their teacher in contrast with the more didactic exchanges which involved girls.

Alongside these issues of classroom dynamics, peer and popular cultures contribute to girls' potential (self) exclusion from mathematics by defining it as a masculine space, creating tensions for girls who are good at mathematics. Thus, Mendick (2005) argued that dominant discourses "inscribe mathematics as masculine and so it is more difficult for girls and woman to feel talented and comfortable with mathematics and so to choose it and do well at it" (pp. 216-217). Walls (2009) argued correspondingly that girls and women in mathematics "are required to don a cloak of invisibility that affords them temporary status as honorary males in a male domain" (p.47). Alternatively, they may position themselves at the periphery of classroom discourse in an alternative mode of invisibility (Rodd \& Bartholomew, 2006).

The research reviewed so far draws on studies in England and Australia. Norway presents an interesting case in terms of the long-standing public circulation of gender equality and equal opportunity discourses which it shares with other Scandinavian countries (see Wedege, 2007). Reporting on girls' and women's participation in Sweden, Brandell and Staberg (2008) note that despite "a fairly good record concerning gender equity" (p. 495), female students comprise $38 \%$ of students in intensive mathematics programmes in upper secondary school, dropping to 
$30 \%$ at undergraduate and $26 \%$ at graduate levels. Investigating the possible reasons for this trend in a large-scale survey based on Leder and Forgasz's (2002) Who and mathematics scale, they concluded that mathematics was more commonly perceived as a male domain than a female domain among upper secondary school students. Furthermore, positive aspects of mathematics (enjoying challenge and interest) were seen as more applicable to boys. Investigation of sub-groups in the sample revealed that these results were due to boys' much stronger adherence to these perceptions, but both girls and boys saw negative aspects (finding mathematics boring and difficult) as more applicable to girls. Also in Sweden, Szabo (2017) reports that boys and girls in accelerated mathematics classes differ in their experience of mathematics. Exploring similar issues in Norway, With and Solomon's (2014) small-scale qualitative study suggests that equity discourses in Norway appear to have little impact on upper secondary school students; they found that girls still positioned themselves within discourses of ability and gender, as "just" hard workers, echoing Brandell and Staberg's findings that girls are seen as needing to work harder than boys if they are to succeed.

With and Solomon (2014) also found that Norwegian upper secondary school students were somewhat conflicted with respect to ability grouping. While they tended to draw on fixed ability discourses to describe it as a beneficial practice, they were anxious not to devalue other students or set themselves above them - potentially invoking the Scandinavian "Law of Jante" (Sandemose, 2000), which emphasises the collective and devalues individual success and achievement, disallowing claims to being better than others. This complex background of equity discourses mixed with pervasive cultural models of mathematics make the moves towards legitimisation of ability grouping described above of particular interest. In this paper, we explore girls' accounts of being in a high ability classroom, and the ways in which they author themselves as mathematics students within this particular context. We focus in particular on the positioning of one girl as a "nerd" as indicative of the social cost of being a "clever girl". We argue that current policy movements towards using ability grouping in order to enhance participation and engagement are misguided and potentially counterproductive, failing to address the discourses that create conditions in which girls must negotiate the delicate balance between being female and being good at mathematics, despite Norway's strong educational ideology of equality of opportunity.

\section{Theoretical framework}

Given the role of cultural models and positionality in the literature on girls' experiences of school mathematics, and of high ability groups in particular, our focus in this paper is on the ways in which they narrate themselves - and each other - as "good at mathematics". Holland, Lachicotte Jr, Skinner, \& Cain's (1998) concept of a "figured world"- "a socially and culturally constructed realm of interpretation in which particular characters and actors are recognized, significance is assigned to certain acts, and particular outcomes are valued over others" (p. 52)-provides a means of understanding the interplay of social position and cultural models within identity narratives. Drawing on Bourdieu's (1990) recognition of the positional power of major structures such as class and gender, Holland et al. incorporate elements of Vygotsky's (1978) focus on our manipulation of cultural resources: the stories, acts and characters that make the world a cultural world contribute to narrativised or figured identities. Bringing these perspectives together with Bakhtin's (1981) concept of "selfauthoring", Holland et al. suggest that we "tell" ourselves and others who we are, by drawing 
on our own histories or culture, within the framework of the discourses that influence our lives: this telling forges our identity.

The lens of figured worlds draws attention to the mathematics classroom as a hierarchical social setting, where participants take up different roles which define who they are in relation to each other - their positional identity. But it also describes it as a setting which draws on, and is constituted by, circulating stories which feed individuals' figurative (narrativised) identities - identities which are predicated on, or endorsed by, cultural models of "who's who" in the classroom. Figurative identities are of particular interest to us here as key markers of shifting possibilities in the enactment of being good at mathematics - a figured world is not fixed, and our positioning of self is not static, but fluid: it reflects and contributes to the sense-making stories which circulate within the world (Solomon, 2012; Solomon, Radovic, \& Black, 2016). Drawing on Jørgensen and Phillips' (2002) use of the concept of discourse order, we can extend this understanding of a figured world by focusing on the tensions and movements within and between competing discourses. Building on Laclau and Mouffe (1985), Jørgensen and Phillips emphasise that discourse is changeable: no discourse is a closed unit, being transformed in constant contact with others in an ongoing process of struggle. Hence, the discourse order can be stable if the various discourses at play are similar, sharing the same commonplace assumptions, but it may be unstable when discourses compete to attribute different meanings to particular acts or utterances (Jørgensen \& Phillips, 2002). The mathematics classroom can thus be seen in terms of discourse order, where there may be several different discourses vying for hegemony. In particular, the value of being "good at mathematics", and the character and status of the actors to whom this label is attached-including their gender characteristics - depends on the discourse that dominates. While those who cross the boundaries of discourse and positioning may resist or threaten the order and force renegotiation of those boundaries, they may equally be forcibly re-positioned within existing bounds by "border guards" (Sandem \& Gaarder, 2003): as Holland et al. (1998, p. 282) point out, the space of authoring is always a contested space.

Femininity and its intersection with mathematics achievement is particularly contested in this context. Francis (2012) points out how assumptions of "masculine" and "feminine" performance assume strict binaries which lead to the kinds of outcomes noted in the research reviewed earlier-“doing maths is doing masculinity" (Mendick, 2006). And yet, if we employ Bakhtin's (1981) concept of heteroglossia (many-voicedness) to look beyond gender essentialism, Francis argues, we can see that the performance of gender is never "pure":

individual productions of gender are shot through with contradiction, and incorporate both aspects of performance generally understood as 'masculine' and 'feminine'; ... these productions of gender are performed ... within a binarised, 'monoglossic' gender system. (p. 3)

For Bakhtin (1981, p. 270), the multiplicity of heteroglossia is the reality in a world in which monoglossia is normative, and it is this normativity which frames the (self)positioning of girls in mathematics. Quoting Butler (2004), Francis (2012) suggests that they risk becoming "impossible subjects",

comprising a fundamental expression of heteroglossia in their direct challenge to, and potential disruption of, the monoglossic gender binary. These 'impossible subjects', by their very existence, reveal the partiality of the monoglossic account, and threaten 
deconstruction of the relational binary ..... [hence] they are so punitively policed and punished for their Otherness ... (p. 8)

In self-authoring as good at mathematics within the context of these "centripetal forces" (Bakhtin, 1981, p. 270), girls may threaten the discourse order of their own femininity, despite the heteroglossia that they are likely to share with each other, and despite the equity discourses which may contribute to their heteroglossic state. In our analysis, we explore the positional and figurative identities at play within their individual and collective narratives, paying particular attention to the policing role of the figure of "the nerd".

\section{Methodology}

Current practice in Norway most commonly implements the recent focus on challenging high achieving students by accelerating the pace of teaching and working with the syllabus for the forthcoming school year. This practice is strongly encouraged by the school authorities in Oslo, where the school in which this study took place is located. It caters for just under 600 students in the 8th, 9th and 10th grades (ages 14-16; 10th grade is the final compulsory year of school in Norway). Students are drawn from a mid to high socio-economic background, and its population is relatively homogeneous ethnic Norwegian. The students in this study were in the 10th grade, and had three one-hour sessions of mathematics teaching a week. One of these sessions took place in the two original (heterogeneous) intake class groups, but the other two sessions involved regrouping students across the two class groups, primarily in accordance with their level of performance in mathematics, with around 18 students in each group. Thus, for two out of three lessons per week, the original two class groups were split into three: two groups representing lower and middle achievers, respectively, and the higher achieving group. These groups differed in terms of curriculum coverage and pace as deemed appropriate by the teacher; the higher achieving group spent less time on the designated curriculum for the grade, studying at a faster pace so that they could also engage with the syllabus for the following grade.

In keeping with Norwegian education policy, grouping was framed as non-permanent: regrouping decisions were made two or three times a year but did not in practice result in major changes for the higher achieving group. Decisions about grouping were made by the teachers involved alone; the school management played no part other than indicate the guidelines for ability grouping, which were that they should provide more help for students who were struggling with mathematics. Hence, the decision to generate a group consisting of students who were high achievers in mathematics was made autonomously by the particular teachers in charge of this year group, framed in terms of the need to help all students regardless of their mathematical level. This decision thus reflected what had become a common Oslo practice and justification for creating and teaching higher ability groups. Gender was not a focus for either management or the teacher in this class, who was male and relatively recently qualified. The students themselves were not told about the purpose of grouping: it was established practice in the school, and the students had experienced such grouping since the 8th grade. Thus, few questions were asked about it, and it was taken for granted as common practice. Certainly, there is no indication in the data of an explicit "official line".

This study focuses on the girls in one such group, which comprised seven girls and nine boys. Their 8th and 9th grade performance in class and in national tests showed that all seven 
girls had achieved grade 5 or 6 in mathematics, where grade 6 is the highest possible mark. The data were collected by the first author, a teacher at the school but never a teacher for these particular students. She attended six lessons as an observer over a period of six weeks; thus, the girls knew that she was familiar with that particular class, and would be able to understand references back to class events during focus groups and interviews. Data collection comprised two focus groups with the seven girls (three and four girls in each group, respectively), held three weeks into the study and followed three weeks later by individual interviews with all seven, three of which are focused on in this paper.

The two focus groups were arranged with help from the teacher to pick girls who would function well as a group and express themselves freely. In addition to asking about their experience of their mathematics groups (both the high ability group and their once a week mixed class group), discussion was prompted by tasks designed to (1) elicit cultural models of mathematics [assess adjectives describing mathematics - exciting, boring, interesting, creative, useful, irrelevant, etc.] and compare it with other subjects, (2) focus on gender and performance in the classroom [discuss statements such as "boys are more interested in mathematics than girls", "I like to compete and get the right answer first", "it's OK to be wrong", "teachers think boys are better at mathematics than girls"] and (3) focus on gender more generally [discuss a newspaper article about girls' greater tendency towards mathematics anxiety in comparison to boys]. These discussions also provided a basis for topics to follow up in the interviews and a means of investigating how individual girls positioned themselves with respect to collective accounts when speaking alone. The interviews thus varied among students, but in addition to issues arising from the focus groups, the interview topic guide asked about the girls' mathematics histories stretching back to primary school, particular teachers who had affected them in some way, their current experience of mathematics and the high ability group, and their future plans.

Although the first author was a teacher at the school, and was known to the students for that reason, they had not been in a teacher-student relationship, and contact outside of the study was avoided. Nevertheless, the fact that the study was undertaken by a teacher at their school is likely to have had an influence of some sort, which we acknowledge and were aware of in analysing the data. This may be offset by the fact that teacher-student relations in Norwegian schools are informal in comparison to other countries, while gathering data from focus groups enables a degree of distance for students in comparison with the one-one interview situation. Care was taken not to discuss the girls with their teachers. The class teacher was new at the school and not known to the first author prior to the study. Full ethics approval was sought and gained from the Norwegian Social Science Data Services (NSD), involving a monitored process of informed consent, participant information, confidentiality and secure data storage. All students agreed to participate, but in order to avoid the possibility that some could feel pressurised to participate due to the status of the first author, their voluntary status was emphasised to parents at parents' meetings.

The focus groups and interviews were audio recorded and transcribed by the first author immediately after they had occurred, so as to retain as much information as possible about body language and mood. Our theoretical position in this paper leads us to notice the cultural models and figures which underpin the ways in which the girls authored themselves and others, with particular attention to the contradictions and contested elements which emerge in accounting for their experience. Following Braathe and Solomon (2015), our analysis consequently focuses on the co-constructed nature of both focus group and interview data, and the 
way in which participants negotiate and draw on particular figures and discourses of femininity in their joint sense-making. We operationalise these relationships within the data as follows:

Co-construction: dialogue that focuses on establishing joint meanings and expectations, for example, what is appropriate behaviour for the girls in the group and how this relates to the meaning of the word "nerd". Meanings are contested and/or negotiated, and key words or phrases are appropriated by interlocutors and redefined or re-used, sometimes in contradictory ways that are not necessarily resolved. In the following analysis, the term "nerd" and its application to a particular person is discussed at length.

Cultural models/figures: references to "known" or shared ideas/types of people that are picked up and used by other participants. They are treated as important, as indicated by their role as reference points for describing actions and characteristics of self and others. In what follows, the figure of the "nerd" emerges as "the elephant in the room" that once raised dominates the discussion.

Our selection of data focuses on the emergence and negotiation of the "nerd" and its insertion into discourses of "acceptable" female behaviour in being good at mathematics. We pursue this theme in analysis of the three interviews as accounts of self-positioning in relation to the "nerd".

\section{Analysis: figures of femininity in clever girls' stories}

In this section, we first explore the figured world of this particular class, as seen through the collective eyes of the focus groups. We pay attention here to what the girls say about gender and their positioning within the class, suggesting in their easy generalisation a discourse order which subtly prescribes the behaviours expected of a girl who is good at mathematics. Emerging from this analysis is a particular proscribed figure - the [female] "nerd". We then turn to a close analysis of three interviews: with Anna, who was planning to keep on with theoretical mathematics, and with Marie and Gina, who were not.

\subsection{Emergence of the nerd}

Many of the focus group prompts invited the girls to talk about gender and mathematics, and they readily compared their behaviour to that of boys. Responding to the newspaper article, which reported on the PISA survey with the headline "Norwegian girls have maths anxiety", they described the boys in the high ability group as surer of themselves in mathematics:

Anna: I think the boys seem a bit more confident in what they do, while the girls are a bit more like, "Is it right, is it right?"

Kristin: Yeah, I think that too.

Anna: Especially if it's a difficult task.

They also felt that they cooperated more than the boys, who they described as competing with each other over how fast they could solve problems. There was an element of competition between boys and girls, but this was different: 
Interviewer (Int): Is there a big difference in how you work and how the boys work in mathematics?

All: Yes !!

Gina and Gro: The boys are competitive, the girls work together.

Int: Yes, do you do that [work together]?

All: Yes !!

Gro: Yes! And sometimes there's competition between boys and girls, but it's just a bit of a laugh.

Gina: And then it's like, "Have you done it? Have you done it?" "Calm down !! I'm trying to work something out here!"

Given the choice of whether they preferred to collaborate or compete, they unanimously chose cooperation; competition was fun only in certain circumstances, against someone they knew well, or someone who was at the same level as themselves. Collaboration meant that they might avoid having to ask for help from the teacher:

Anna: Amelia and I often cooperate, we work well together.

Int: Do you feel that you benefit from that?

Anna: Yes. Also it's a bit like, when neither of us understands it and we talk about it, maybe we will both understand. If there's anything I'm a bit unsure of, I don't want to ask the teacher. That would be a bit of a defeat. I don't want to give in.

Int: So asking Amelia is better than asking the teacher?

Anna: Yes, well it's a bit like that I have to try first before I ask him.

This exchange illustrates another important feature of the girls' self-authoring-a preoccupation with how they were seen by others. The grouping system was officially labelled "rokeringsgruppe" (literally, "rotation group"), but the students themselves rather revealingly called it "smartegruppa" - the "smart group". The girls were concerned with how they were seen by the teacher, and wanted to have a reputation as good at mathematics. In response to the statement "Teachers think boys are better at mathematics than girls", both focus groups hotly disagreed. Anna elaborated on what the "real" differences are:

Anna: What I think now is that boys are good at maths, but maybe girls are a bit more careful. So they might give it a bit more thought, as they do in the lessons, write it down and really understand it. It might give them a few extra marks.

Despite their concern, it was not acceptable within their own discourse order for a girl to act as though she was getting high marks, and especially not the best marks. In one of the focus groups, the concept of a "nerd" came up in the context of Gro's ruminations on how she is perceived by students who are not in the high ability group:

Int: You say "smart group", you call it that?

Other students: Yes!

Gro: There are quite a few [in the mixed ability group] who don't actually know that I'm in the [high ability] group, but I do notice, though, that when others who are in the group put their hands up [in a mixed ability lesson], then others I'm sitting next to say like "Now she's guaranteed to be right, she knows for sure!" If the answer is wrong, then it's a bit of a bigger thing than if one of the others had given a wrong answer.

Gina: We have some people who create an image of the "smart group" here, some real nerds. 


\section{Gro: Yes!}

Gina: They have to sort of have an answer to everything.

Gro: But imagine how it is when they get the answer wrong then, how they [the others] are thinking then. They think straight away, "oh, she got it wrong".

Gro and Gina's co-construction here sets out implicit rules for how to behave as a higher ability girl: it should not be obvious, and making it so by always answering is risky (Gro) and invites the label "nerd" (Gina). As the interviewer probes for a definition of "nerd", the girls attempt to explain its complexity, and in doing so, Gina presents an exemplar:

Int: But when you use the word nerd ..

Other students: It's not necessarily a bad thing ..

Gro: But I don't think that we have anyone who is a proper geek nerd.

Int: Is it that a nerd is good at maths?

Other students: Yes! But other things too.

Gro: But for me it's like, with a nerd, just because someone is good in a school subject and schoolwork it doesn't mean that they become a nerd. It's more like that if you are with your friends and you would rather read books than talking to those around....

Int: So it's about a social thing?

Gro: Yes, that's right, I don't think there's anyone in the class that fits that description. Sigrid: I think that being a nerd geek is more about the social side than ..

Gro: [interrupts] ..yes, because there are lots of people who are very good at school that aren't called nerds at all.

Gina: I don't think so. There's one in our class, as everyone here knows. I know this person from primary school. She wasn't always a nerd - yes, it's a girl. Since she became a nerd and I'm not a nerd it got difficult because she got interested in other things. It's a bit strange really.

Gro: I don't think she's such a nerd. I know of people who are quite a bit worse!

Gina: I've heard everyone say that she's a nerd one way or another, I've heard quite a few say it, but I don't think that she's a nerd, because I know her.

Gro: Maybe it's more that there are boys in the class who say it.

Gina: Yes! They say she's a nerd, and then when I think of her, even though I know she's not a nerd in her social life, in my head she automatically becomes a nerd at school.

Several issues relating to the discourse order come to the surface within this heated exchange. First, as we have seen, it is positive to be seen as clever in this group. However, it is also the case and for some reason worthy of comment that not everyone in the whole class group knows how "clever" several of the girls are; this appears as a main theme in their self-authoring in both focus groups and individual interviews. It appears that, within the discourse order of this group of girls, it is good to be "clever", but not to act in such a way that it is made explicit. Given the emphasis on "cleverness" in the figured world of the high ability group, the question arises as to how it is also the case that it is not desirable for the girls to act as though they are good at mathematics. One possibility for this tension may be that the Law of Jante is in operation here, but alongside this, or replacing it, there is evidence that the figure of a nerd is part of the discourse within this group, and the risk of "acting clever" in terms of being labelled as a nerd is real.

Also noticeable is the unclear and contested nature of the idea of a "nerd". The girls' discussion of what it means seems to centre on the idea that an essential characteristic of being 
a nerd is that someone is not really sociable, valuing work over friends, which is clearly seen as negative. But there are complexities over and above this; we note that it is Gina who introduces the idea in the first place, but in the following exchange, Gro challenges the claim that there are nerds in the "smart group". Gina maintains that there is someone who fits that description but for some reason does not name her-her "yes it's a girl" indicates to the others who she means. They are clearly friends, or once were anyway, and Gina is keen to say that their friendship is not so strong now, because she (Gina) is not a nerd. Gro resists applying the term to the girl in question-Anna, as it turns out - and Gina takes a step back in her argument, saying that she knows Anna very well, and that she is not really a nerd. They finally construct an account of how she might be (unfairly) labelled as a nerd by the boys in the class, and Gina compounds her withdrawal by blaming the boys for influencing her thinking even when she disagrees. Gina's self-positioning in this exchange is interesting, since although she is forced to backtrack on her distinct "othering" of Anna in the face of Gro's arguments, she has in the meantime made it clear that she is not a nerd, effectively distancing herself from this category. We return to Gina's self-authoring as a "clever girl" later in this paper, but note for now how her talk reflects - and perpetuates - the discourse order within the group which made being good at mathematics, and publicly so, a challenging position for a girl. Their preoccupation with how they are seen and the subtle balancing act of visibility and invisibility it involved was notable in much of the data, as the following sections show.

\subsection{Presenting Anna: mathematics at a cost?}

Anna was assessed by her teacher as one of the highest achievers in the group. She said that mathematics and science were her favourite subjects, and she intended to pursue theoretical mathematics and physics in order to become an engineer. She liked the high achievers' group, because it was challenging and motivating, and there was little need for repetition of material. She also described herself as competitive ....

Anna: I have a competitive instinct. It's like, "I don't understand this, but I'll do it". Int: So you like a bit of competition when you're working, or do you prefer cooperation?

Anna: I like to cooperate, but [only] if I've understood it first, it's a bit odd.

... and as having a tendency to make careless mistakes, as in this passage, where she talks about the teacher's perception of her:

Int: Are you concerned that someone important thinks you are good or is it mostly for yourself?

Anna: No it's really most for myself. But I am quite concerned, since because of careless mistakes I often get 5+ [ie, not the top mark of 6] for tests, so I'm quite concerned that the teacher should see that I'm better than a 5+, but he knows that.

Int: You say that, you know he knows. When do you think he's seen that?

Anna: I think it's in lessons, it seems to me anyway that he knows. So I think it's in lessons. When he explains things to me, he doesn't have to say things that many times, and if we've been doing [mathematics from the next grade], he asks, "was this OK, you understood it?” And usually I've understood. Then I know I'm doing OK. ....

Int: So what happens in the lesson is important to you?

Anna: Yes, it's important. 
Anna's self-authoring as competitive and careless departs, then, from the account generated in the focus groups of how girls behave in the high ability group - an account which Anna herself has contributed to. In her interview, she raises the issue of being labelled as a nerd:

Int: When we talked in the focus groups it came up that being labelled as clever wasn't always positive. Do you recognize that? What do you think about that?

Anna: Ehh, it's, well, being labelled as clever, clever is one thing. But I go around being called a nerd quite often.

Int: What do you think about that?

Anna: I think it's that they see me as not having to work hard to get good grades. I don't really work that hard, so I think it's like that, it starts to become pretty upsetting after a while. So when I say that it's starting to get upsetting, they say that it's positive, yes, "you are smart". But the tone they say it in isn't exactly pleasant [long pause, close to crying]. So it's a bit upsetting, it's one of the reasons I'm going to high school in the city. There are a lot like that [ie 'smart'], so then there's no going around talking that way to others, they're all like that.

It seems that Anna pays a high price for the way in which she is "clever" in mathematics. Despite acting during class within the parameters of the discourse order which prescribes appropriate (invisible) behaviour for a girl ("I say a lot in other lessons, but in maths if I'm not sure about it, I won't put my hand up"), it seems that Anna's engagement in mathematics somehow crosses the boundaries of possibility, challenging gender binaries in her heteroglossic self-authoring as competitive, careless and "not having to work that hard". While the girls themselves seem unable to agree on her exact status as a nerd, Anna is most definitely the girl they do not want to be, as we have already seen from the focus group discussion and Gina's part in it. In the next section, we look more closely at Gina and Marie, noticing how the storying of Anna runs through their self-authoring as, independently of each other, they distance themselves from the figure of the nerd and from Anna herself.

\subsection{Gina and Marie: not Anna, not mathematics}

We have identified Gina and Marie as interesting cases here because while both were strong in mathematics (Marie was possibly the strongest in the whole group according to her test marks and her teacher's judgement, while he rated Gina among the strongest students he taught), neither intended to pursue theoretical mathematics beyond the current year. Marie planned to choose a social sciences mathematics pathway, and wanted to study psychology or another social science, meaning that theoretical mathematics was not part of her future. Gina's favourite subjects were arts and crafts, and she preferred Norwegian, English and science to mathematics; her chosen pathway also meant that she would not take mathematics any further than the minimum required.

Even though mathematics was not her favourite subject, Gina said that she liked to do well at it and to engage with more challenging mathematics; understanding was very important to her. However, she described herself as unsure, feeling the need to justify her place in the group:

Gina: I'm unsure of myself.

Int: What causes that, do you think?

Gina: Simply that we have a new teacher, and I had to prove something ... I feel like that when you sit in this group here [the high ability group] then it's like that, you have to be smart!

She also describes feeling uncomfortable performing in front of the other students: 
Gina: Once I had come up to the board to do a task, I was so unsure of myself, I didn't manage anything. I did everything wrong, and it was a really easy bit [of the problem]. $\ldots$ and I was so stressed out because I knew everyone was watching.

Gina had a lot to say about "being clever" in her interview, and the subject of Anna came up, because -according to Gina - her own grades were better than Anna's in fact:

Int: Do you feel that you're labelled as clever?

Gina: No, it's just that, you can like decide whether you want that label or not, by behaving like that, bragging that you are good and stuff. We've this person in the class we call our nerd, because that person likes to have compliments. It's not something silly, it's just that she's called smart all the time, and anyway, I often get better grades than her. But she's still the smart one, so it's sort of like, sometimes I get better than her and sometimes she gets better than me, and I'd say that we are on the same level. But I don't want to be called smart anyway, so a lot of people are surprised that I get the same grades as her. They just - "you?"

Int: But why wouldn't you want to be called smart in the first place?

Gina: I just want to be normal, basically.

Int: So the most important thing for you is to be clever for yourself?

Gina: Yes. It's also that I like, I like the others to know that I get good grades, but I don't like to say it. So I prefer to be clever for myself.

There are many complexities in this speech, in which Gina authors herself in reference to Anna. For Gina, someone who is clever has a choice as to whether they are labelled as such, depending on their behaviour. While she and Anna are at the same level academically, Gina contrasts Anna's "bragging" with her own silence on the issue, describing a kind of academic "coquetry" in line with the general discourse order among the girls - wanting to be noticed but not being seen to seek notice. She distances herself from Anna here, protecting herself from sharing the same fate of rejection as a nerd, authoring as someone who avoids putting themself forward in the same way, keeping quiet about her achievements: being called "smart" (and by implication allowing oneself to be called so) is not being "normal".

Marie rarely spoke in the focus group, but in her interview described herself as good at mathematics, and liking the challenge of the advanced work in the group. She attributed higher significance to doing well in mathematics in comparison with other subjects, and enjoyed doing better than other students:

Int: Is it different in maths than in other subjects, to get a good grade in the subject? Marie: Yes it's probably a bit more important, I see it as a bit more important in a way. As I said, there are a lot of [students] who aren't doing so well, so it's extra fun.

Despite this pleasure, Marie explained that she did not like to attract attention to herself by contributing to class discussions, for fear of being wrong. But conversely, like other girls, she was quite emphatic that cleverness is best hidden, and secretly enjoyed:

Int: When we talked in the group, you talked about how easily you got the label "smart". How do you feel about that?

Marie: It's not like so many look at me and think "she's smart", or something like that. But I think it's fun to be smart.

Int: Yes, you like it? 
Marie: Yes, there are some that are just like that .... [indistinct] ... some like to be nerds, that think it's a lot of fun in school. Anna is currently very taken up with it, very happy with it and will do well and stuff. I want to do well too, but I don't think people look at me as the smartest, or the most clever or the best ...

Int: And you think that's okay?

Marie: I think that's okay. People know that I'm smart, but not the smartest. Sometimes people think that if there's a problem that's difficult, they think that "yes, maybe she's managed to do it" and then maybe I am the only one who has managed it. But I'm not the first person people think of really.

Int: How do you feel about labelling in general?

Marie: It's okay if you have a lot of friends who have the same label as you, but it's not fun to just be labelled as smart.

It seems, then, that Marie was pleased to be good at mathematics; it was fun to be so, and to be better than others as long as she was not labelled as "smart". She too introduces the subject of Anna in this context. Unlike Gina, who blames Anna for her position as the class nerd, Marie claims that Anna enjoys it — but we know that this is not the case. Their independent analysis of Anna's nerdiness as breaking the convention of invisibility suggests that she plays a significant role in the girls' authoring of self. Although, in the focus group, the girls eventually blame the boys for the labelling of Anna, Gina and Marie's individual interviews suggest that in fact the positioning of Anna as a nerd has much more importance within their own grouping. We might therefore argue that Gina and Marie are acting as discourse border guards within their own discourse order-Anna crosses the boundary too often. But while she might present a threat to the discourse order and to the assumption of gender binaries within it, the labelling of Anna's heteroglossic challenge as enacting the figure of the nerd enables Marie and Gina and the other girls to shelter from the dangers of being a "clever" girl by being not Anna.

\section{Discussion}

For some years, researchers have been concerned with the impact of cultural assumptions of mathematics as a male domain, and the difficulties that this presents for being a girl who enjoys mathematics and is good at it, particularly those who find themselves in high ability groups. In this paper, we have explored the detail of girls' self-authoring as good at mathematics within a context which we might have expected to challenge at least some of the gender binaries which are applied to mathematics - Norway's explicit equity agenda. In doing so, we respond in part to Brandell and Staberg's (2008) call for explanations of the gendered attitudes they found, and for girls' reluctance to study further mathematics. We also respond to changes in the educational/political climate in Norway, where new legitimization of ability grouping is built on an assumption of raising aspirations by providing the best opportunities for all students. Despite these contextual agendas for change, our analysis reveals the centripetal force of a discourse order which prescribes girls' behaviour in mathematics in a way which means that in choosing mathematics they risk - and must guard against-becoming one of Butler's (2004) "impossible subjects".

Our analysis shows that the girls' discourse order is bounded by implicit rules which position girls as needing to be "clever" but not to be seen or act as such. Their major topics of discussion concern how they are seen by others - as worthy of their place in the high ability 
group, but also as not so clever (or acting as such) that they are nerds. The very contestedness and lack of clarity of the characteristics of this figure keeps them on their toes: they are vulnerable in this situation, and must distance themselves from it. We can see Gina and Marie as discourse border guards, alert to the challenge presented by heteroglossic performances such as Anna's, and we can see them contributing to her construction as a nerd, with far more significance for them than the boys they try to blame.

This analysis does not, of course, mean that the girls could just decide to be differentalthough they try to suggest that Anna has a choice, she does not, and neither do they, since they exist in a context, even in egalitarian Norway, where gender discourses are powerful determinants of behaviour. Nor do we intend to imply that Anna and all girls like her will inevitably experience the isolation she describes. Rather, her case, and her importance in the self-authoring of other girls, is illustrative of the intersection of discourse and figure in a local figured world. As Francis (2012) points out, "productions of gender are performed within local socio-economic environments and to specific audiences, to signify in particular ways within a binarised, 'monoglossic' gender system" (p. 3), and in other contexts a less - or differentlybinarised order may prevail.

But we doubt the supposed benefits of recent Norwegian education policy which aims to unproblematically increase participation and/or raise standards by grouping strong students together. Clearly, high achieving girls can enjoy mathematics and the challenge of more advanced mathematics, but the environment of the high ability classroom is otherwise toxic in terms of gender performance. It fails to develop them both in terms of achieving their full academic potential (they are still turning away from the high status theoretical mathematics which will open doors to STEM areas of study), and in terms of developing the "whole person"- at the same time that they benefit from working together-they fear the consequences of public performances in which they must walk a tightrope between being seen to fail and being "too good". Our analysis suggests that, given that Marie and Gina are both turning away from higher status mathematics while Anna feels that she has to leave and go to another school in order to pursue it, achieving genuine equal opportunity in mathematics requires something very different.

Compliance with ethical standards Full ethics approval was sought and gained from the Norwegian Social Science Data Services (NSD), involving a monitored process of informed consent, participant information, confidentiality and secure data storage.

Open Access This article is distributed under the terms of the Creative Commons Attribution 4.0 International License (http://creativecommons.org/licenses/by/4.0/), which permits unrestricted use, distribution, and reproduction in any medium, provided you give appropriate credit to the original author(s) and the source, provide a link to the Creative Commons license, and indicate if changes were made.

\section{References}

Bakhtin, M. (1981). The dialogic imagination: Four essays by M.M. Bakhtin. Edited by M. Holquist, Translated by C. Emerson \& M. Holquist. Austin: University of Texas Press.

Bartholomew, H. (2005). Top set identities and the marginalisation of girls. In M. Goos, C. Kanes, \& R. Brown (Eds.), Proceedings of the $4^{\text {th }}$ international Mathematics Education and Society conference (pp. 69-77). Brisbane: Griffith University.

Bjørkeng, B. (2011). Jenter og realfag $i$ videregående opplcering. [Girls and science in secondary education]. Report 2011/03. Oslo: Statistisk sentralbyrå [Statistics Norway]. 
Black, L. (2004). Differential participation in whole-class discussions and the construction of marginalised identities. Journal of Educational Enquiry, 5(1), 34-54.

Boaler, J. (1997a). Experiencing school mathematics: Teaching styles, sex and setting. Buckingham: Open University Press.

Boaler, J. (1997b). When even the winners are losers: Evaluating the experiences of 'top set' students. Journal of Curriculum Studies, 29(2), 165-182.

Boaler, J., Wiliam, D., \& Brown, M. (2000). Students' experiences of ability grouping — disaffection, polarisation and the construction of failure. British Educational Research Journal, 26(5), 631-648.

Bourdieu, P. (1990). The logic of practice. (R. Nice, Trans.). Palo Alto: Stanford University Press.

Braathe, H. J., \& Solomon, Y. (2015). Choosing mathematics: The narrative of the self as a site of agency. Educational Studies in Mathematics, 89(2), 151-166.

Brandell, G., \& Staberg, E.-M. (2008). Mathematics: A female, male or gender-neutral domain? A study of attitudes among students at secondary level. Gender and Education, 20(5), 495-509.

Butler, J. (2004). Undoing gender. New York: Routledge.

Forgasz, H., Becker, J. R., Lee, K.-H., \& Steinthorsdottir, O. (Eds.). (2010). International perspectives on gender and mathematics education. Charlotte: Information Age.

Francis, B. (2012). Gender monoglossia, gender heteroglossia: The potential of Bakhtin's work for reconceptualising gender. Journal of Gender Studies, 21(1), 1-15.

Holland, D., Lachicotte Jr., W., Skinner, D., \& Cain, C. (1998). Identity and agency in cultural worlds. Cambridge: Harvard University Press.

Jensen, F., \& Nordtvedt, G. (2013). Holdninger til matematikk [Attitudes toward mathematics]. In M. Kjærnsli \& R. V. Olsen (Eds.), Fortsatt en vei å gå [Still a way to go] (pp. 97-117). Oslo: Universitetsforlaget.

Jørgensen, M. W., \& Phillips, L. (2002). Discourse analysis as theory and method. London: Sage.

Laclau, E., \& Mouffe, E. C. (1985). Hegemony and socialist strategy. Towards a radical democratic politics. London: Verso.

Leder, G. C., \& Forgasz, H. J. (2002). Two new instruments to probe attitudes about gender and mathematics. Washington, D.C.: ERIC, Resources in Education ED463312/TM033744.

Mendick, H. (2005). A beautiful myth? The gendering of being/doing 'good at maths'. Gender and Education, $17(2), 89-105$.

Mendick, H. (2006). Masculinities in mathematics. Berkshire: Open University Press.

Ministry of Education and Research (1998). Lov om grunnskolen og den vidaregåande opplæringa (opplæringslova) [The law on primary and secondary education (Education Act)] Oslo: Ministry of Education. Retrieved 10th January 2018 from https://lovdata.no/dokument/NL/lov/1998-07-17-61.

Ministry of Education and Research. (2014). Rapport fra ekspertgruppa for realfagene [Report from an expert group of science and mathematics education]. Oslo: Ministry of Education and Research.

Nissen, P., Kyed, O., Baltzer, K., \& Skogen, K. (2012). Talent i skolen [Talents in School]. Namsos: Pedagogisk Psykologisk Forlag.

Nordtvedt, G. (2013). Resultater i matematikk [results in mathematics]. In M. Kjærnsli \& R. V. Olsen (Eds.), Fortsatt en vei å gå [Still a way to go] (pp. 67-92). Oslo: Universitetsforlaget.

Paechter, C. (2001). Gender, reason and emotion in secondary mathematics. In P. Gates (Ed.), Issues in mathematics teaching (pp. 51-63). London: Routledge Falmer.

Rodd, M., \& Bartholomew, H. (2006). Invisible and special: Young women's experiences as undergraduate mathematics students. Gender and Education, 18(1), 35-50.

Sandem, E. N., \& Gaarder, F. (2003). Larerens betydning for elevenes trivsel. Om makt, omsorg og annerkjennelse i relasjonen laerer-elev [The importance of the teacher for students' well-being. Power, care and recognition in teacher-student relationships.] Oslo: Oslo University Press, available from http://secure. kolofon.no/hio/index.aspx?pid=3121\&docid=140.

Sandemose, A. (2000). En flyktning krysser sitt spor: fortelling om en morders barndom [A fugitive crosses his tracks: Tale of a killer childhood]. Oslo: Aschehoug.

Skogen, K., \& Idsøe, E. C. (2011). Våre evnerike barn [Our gifted children]. Kristiansand: Høyskoleforlaget.

Solomon, Y. (2007). Experiencing mathematics classes: Gender, ability and the selective development of participative identities. International Journal of Educational Research, 46(1-2), 8-19.

Solomon, Y. (2012). Finding a voice? Narrating the female self in mathematics. Educational Studies in Mathematics, 80(1-2), 171-183.

Solomon, Y., Radovic, D., \& Black, L. (2016). "I can actually be very feminine here": Contradiction and hybridity in becoming a female mathematician. Educational Studies in Mathematics, 91(1), 55-71.

Szabo, A. (2017). Matematikundervisning för begåvade elever - en forskningsöversikt [Mathematics education for talented students - a research overview]. NOMAD, 22(1), 21-44. 
Turmo, A. (2007). Norske skoleelevers selvregulerte læring [Norwegian pupils' self-regulated learning] Utdanning 2007 [Education 2007]. Oslo: Statistisk sentralbyrå [Statistics Norway] Retrieved 10th January 2018 from http://www.ssb.no/a/publikasjoner/pdf/sa90/kap-4.pdf.

Vygotsky, L. S. (1978). Mind in society: The development of higher psychological processes. (M. Cole et al., Ed.). Cambridge: Harvard University Press.

Walls, F. (2009). Whose mathematics education? Mathematical discourses as cultural matricide? In P. Ernest, B. Greer, \& B. Sriraman (Eds.), Critical issues in mathematics education. The Montana mathematics enthusiast: Monograph series in mathematics education (vol. 6, pp. 45-52). Charlotte: Information Age Publishing.

Wedege, T. (2007). Gender perspective in mathematics education: Intentions for research in Denmark and Norway. ZDM The International Journal on Mathematics Education, 39, 251-260.

With, K., \& Solomon, Y. (2014). Choosing mathematics in Norway and England: Discourses of gender, equity and choice. Philosophy of Mathematics Education Journal, 28 (October 2014) Retrieved 10th January 2018 http://socialsciences.exeter.ac.uk/education/research/centres/stem/publications/pmej/pome28/index.html. 